\title{
Assessment of Contribution Factors to Defects in Hall of Residence in Two Selected Tertiary Institution in South West, Nigeria
}

\author{
Ibrahim-Adedeji K.B. \\ Department of Urban and Regional Planning,Lagos State Polytechnic, Ikorodu, Lagos, Nigeria
}

\begin{abstract}
This paper focuses on the contribution factors of building defects in tertiary institution buildings in Nigeria.Several building defects were commonly found in Nigerian tertiary school buildings. Building defects has become ordinary phenomena in the construction industry which has negative impacts on schools, in the means of building performance, health and safety aspects and overall environmental conditions, teaching and learning processes. Thus, this study is designed to identify the common building defects faced by school buildings in two selected tertiary institution in the south westof Nigeria. Then, a thorough inspection were conducted and the respective defects are recorded with the aid of photographic medium. As the outcomes from the interview between researcher, students' and person-in-charge from institution, the main factors contributing to those building defects had been determined. Besides, appropriate mitigation solutions on the building defects have been offered, which are extremely essential in retaining a healthy and serviceable school building.
\end{abstract}

Keyword:- Assessment, Building Defects, Contribution Factors, Tertiary Institution

\section{INTRODUCTION}

Nigeria is in the intermediary phase of development and industrialization whereby many construction projects are being developed. There are many projects that have been constructed such as recreational buildings, commercial buildings, residential buildings, institutional buildings and industrial buildings. The project of institutional buildings includes educational buildings, hospital buildings and government/civic buildings (Ikpo Johnson, 2006).There are a great number of building defects arose and being reported officially by mass media, especially on defects with educational buildings Ahzahar; Karim; Hassan and Eman, (2011). There are numerous defects which are common to school buildings' components such as roofs, walls, floors, ceilings, toilets, doors and windows. These defects may cause unexpected accident and even death Soleimanzadeh and Othuman, (2013). For example, in 15 September 2015, students union government of ObafemiAwolowo Organized a press conference atOsogbo, the capital ofOsun state to show to the world the level of housing deterioration in the school. Also on 28 September, 2015 the students union of University of Lagos, Akoka shut down school, due to the situation of defects in hall of residence. The cases reported above, indicate that defects can be concluded as fatally disparaging and critical because they bring impairment to their users and the building itself; causing damage, serious injuries and death. Therefore, a study is important to investigate the contribution factors of those defects in order to create a safe building. (Sui Pheng, 2001);(Ikpo Johnson, 2006).

The causes of building defects must be identified at the early stage of the study. The next step was to identify the significance and objectives of the study as well as outlining the scope of study in order to achieve the set objectives. The literature has critically reviewed from a variety of sources such as books, Internet, journals, articles and unpublished thesis. Visual inspection was carried out on the selected schools to determine their current building condition. Two tertiary institutions in south west, a polytechnic and a university (OAU and YABATECH) were selected as case in this study. The building defects found were recorded and the data were collected for data analysis. After that, the researcher concluded the findings and provided recommendations to rectify the problems. Three approaches had been utilized throughout this study to gather reliable and relevant data such as conceptualization, literature review and interviews?

\section{RESULT, ANALYSIS AND DISCUSSION}

Two tertiary institutions were selected as case studies. All data were collected through visual inspections and interview sessions between the researcher and people involve such as technical staffs or maintenance officers and students' in the institution.

\subsection{Peeling Paint}

Peeling of paint was one of the most common defects which were critically found on the building façade, especially on the plastered walls, ceilings, beams and columns. These components were consistently exposed to

DOI: $10.9790 / 0837-2108085864 \quad$ www.iosrjournals.org $\quad 58 \mid$ Page


sunlight, rain, wind and dampness, resulting in peeling paint Othuman and Wang, (2011). The excessive exposure spoiled the surface of paint and thus the surface became chalky, flake and blistered. The problem of peeling paint in schools mostly occurred on the walls, internal or external. The paint on ceiling was also gradually peeled off due to the presence of moisture.
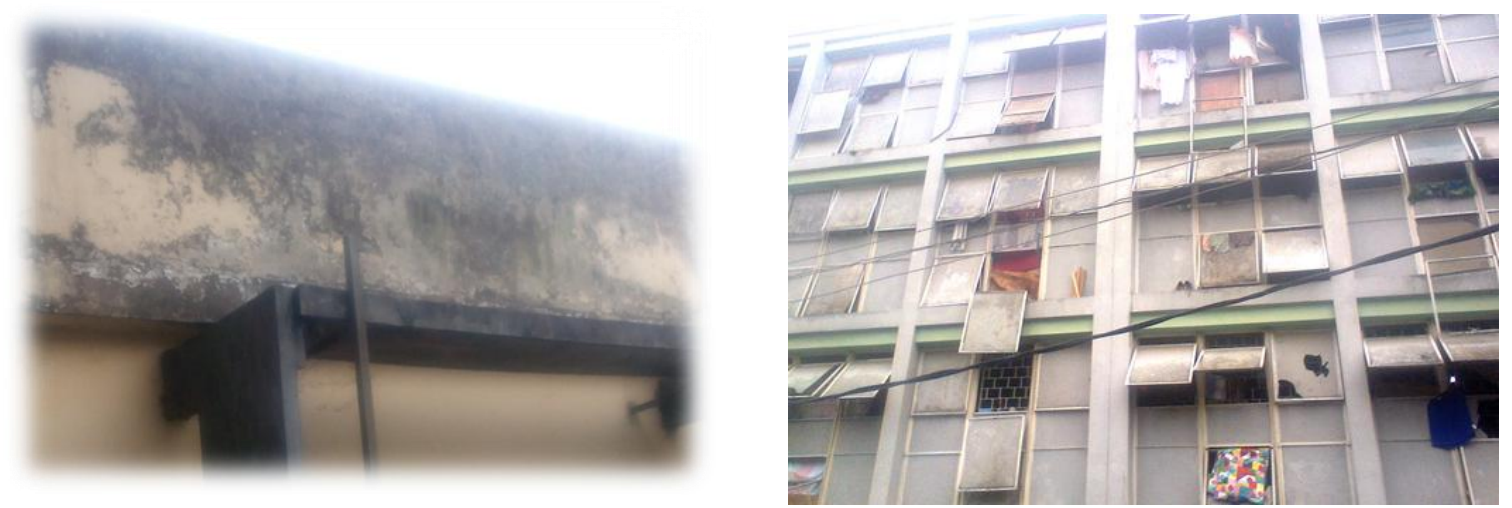

Figure 1a:Peeling and Cracking in Paint and Glass

\subsection{Dampness}

Dampness in schools resulted from water incursion either from internal sources (e.g. leaking pipes) or external sources (e.g. rainwater). This defect became a serious problem when various materials in the school buildings became soak for extended periods of time. Besides, excessive moisture in the air due to poor air ventilation system inside the buildings can also lead to dampness Othuman and Wang, (2011). The common type of dampness found in school buildings is penetrating damp. Dampness was found on the ceiling and wall due to the ingress of water. The classrooms, especially on the top floor, were greatly affected by dampness of ceiling as the roof tiles were missing or blown away by wind. The rainwater penetrated directly into the building itself, resulting in dampness (Fig. 1a; 1b).
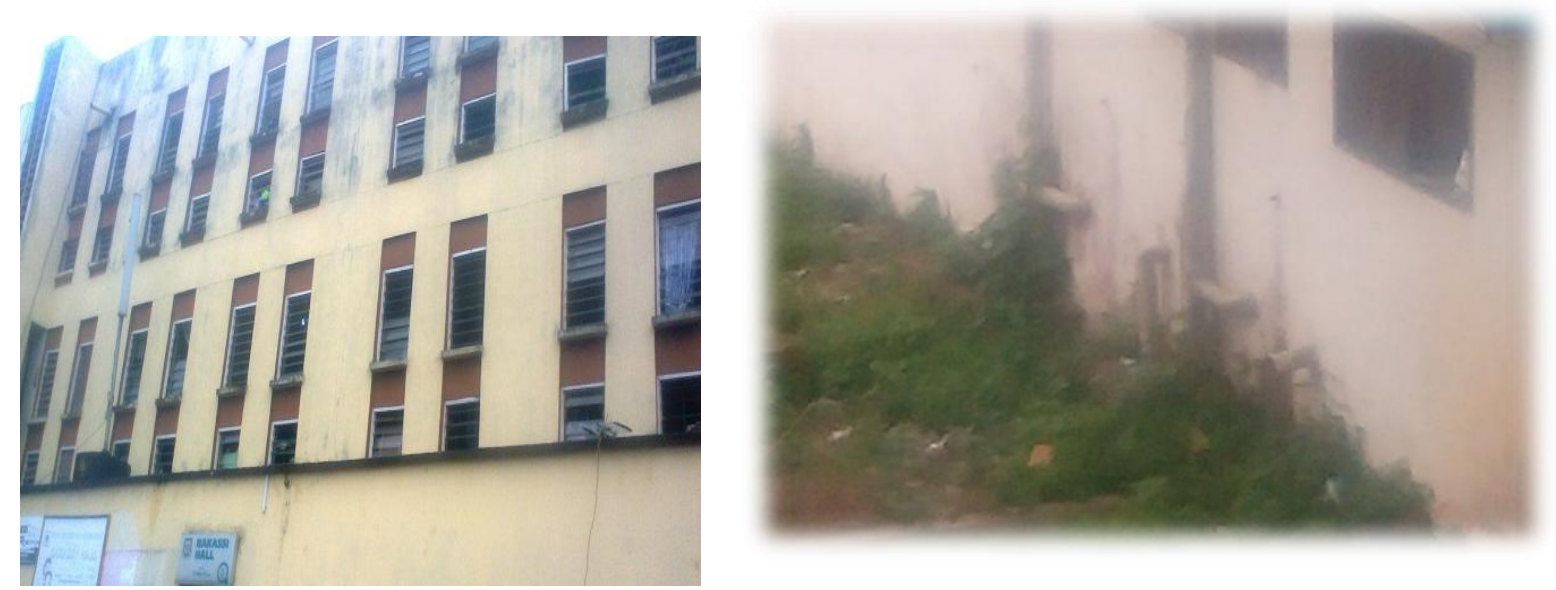

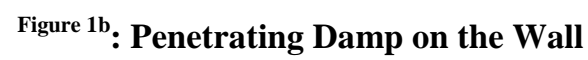

Dampness can arise from unintended water caused by leaking pipes, gutters and flashings Othuman and Wang, (2011). The leaking water penetrated into the wall, resulting in horrible water stains. Under long term of dampness penetration and poor ventilation within the building, excessive moisture promoted the growth of mould on the surface of wall (Fig. 1b).

The growth of mould and fungi are ordinary consequences caused by excessive dampness. Mould and fungi will grow when they gain enough moisture and nutrients Soleimanzadeh, and OthumanMydin, (2013). However, the growth of mould causes a lot of problems to the school environment. It not only physically affected the appearance of the building structure, but also led to plenty of health illnesses to the students and staffs.

\subsection{Discolouration}

It was common to found the discoloration of paintwork in the inspected school buildings. Surface discoloration of paintwork found was in brownish, blackish and yellowish colours. This defect is often related to 
the presence of dampness or biological attack Chong, and Low, (2006). Mould grew aggressively on the surface of paintwork where there is excessive moisture, resulting in discoloration. A simple repainting will not correct the problem for long. Furthermore, serious discoloration will lead to structural damage and appearance damage.
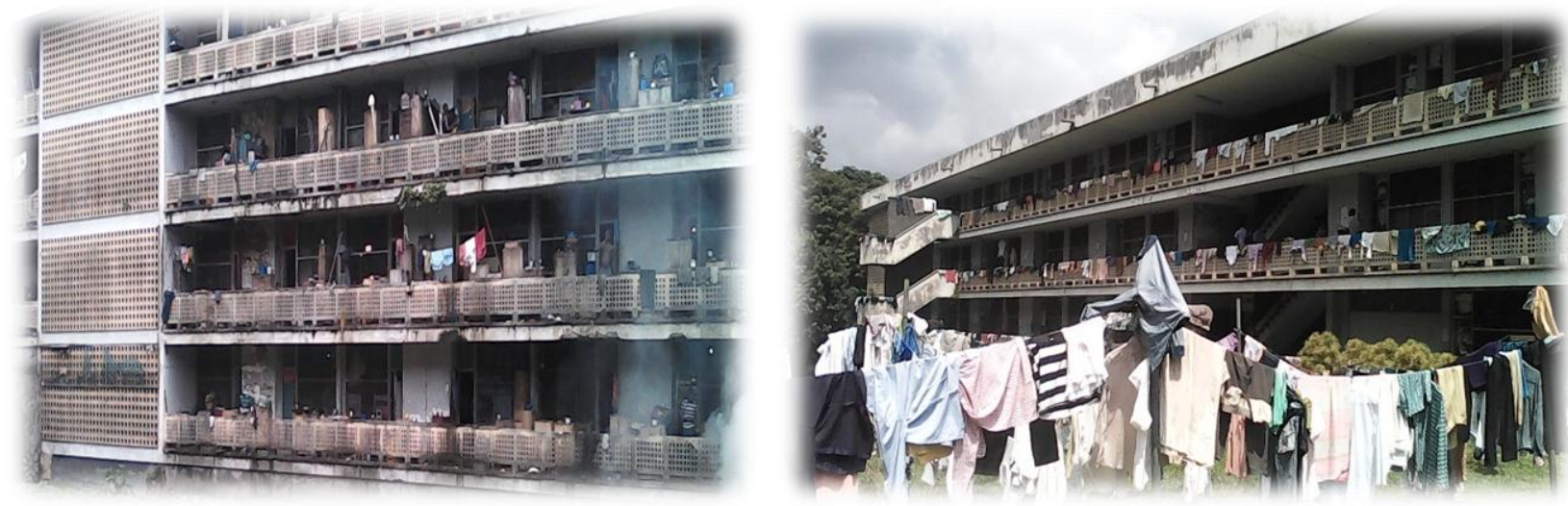

Figure 2a; 2b: Discoloration in Building

\subsection{Timber Decay}

Timber was widely used as a building material in most Malaysian school buildings. However, this type of material can be deteriorated easily due to several reasons, such as aging, dampness or wear and tear OthumanMydin, (2013).

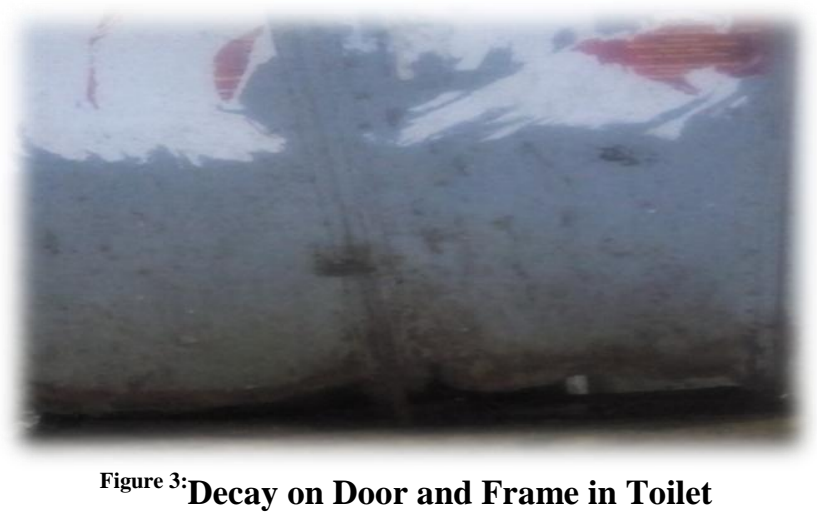

The problem of timber decay was mainly found on door frames, window frames, timber roof struts and ceiling battens. Those components exposed to moisture which was the main critical element in the timber decay process. While, some timber materials decayed because of aging, e.g. ceiling battens. Fig. 3 illustrates the timber door frames in toilets that suffered from the worst situation because they were highly exposed to water and subsequently caused deterioration OthumanMydin, (2013). This type of timber decay was also known as wet rot. Wet rot was the most common type of timber decay in which the fungus feeds on timber; the timber must be damp or wet enough for the fungus to thrive and continue the rotting process. Timber decay occurred if the timber becomes sufficiently wet, with the present of oxygen and nutrients.

\subsection{Cracking}

Cracks happened on the various elements in school buildings such as walls, ceilings, beams, columns and even floors (Fig. 4 and Fig. 5). There were many structural and non-structural cracks found. Structural cracks took place in walls, beams and columns. However, non-

structural cracks usually happened in plaster or other finishes with cement rendering Sui Pheng, Wee, (2001). Different types of cracking such as vertical, horizontal, diagonal and hairline were found in the school buildings. 


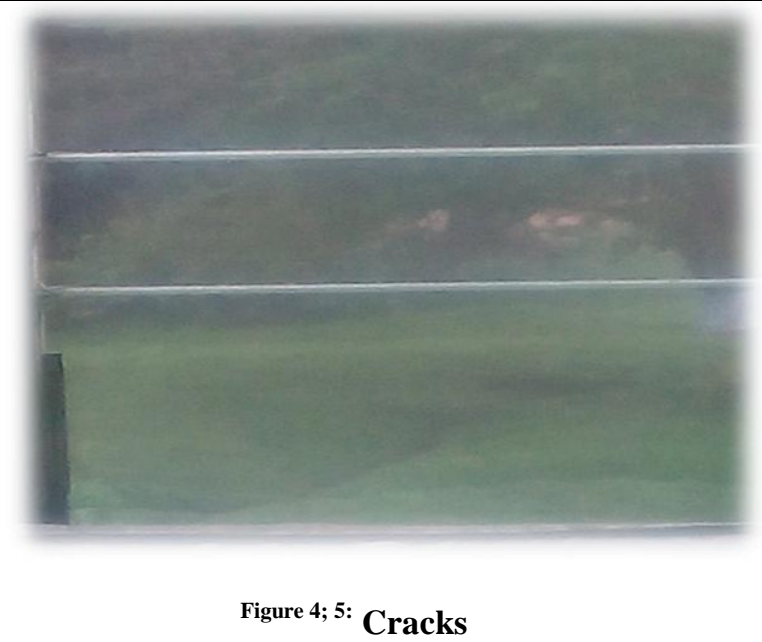

Some parts of the inspected schools showed serious cracks while some only showed minor cracks.

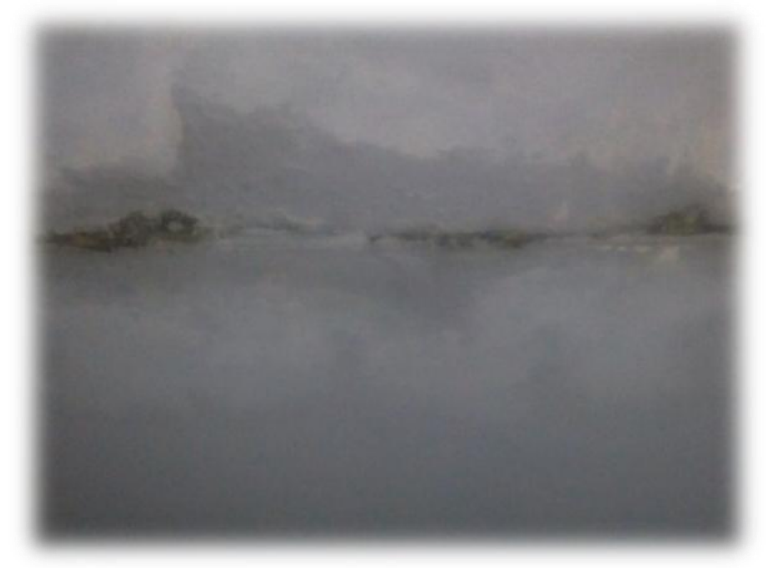

From the inspection, cracks in wall were in various directions and varying in width from fine hair cracks to $5 \mathrm{~mm}$ or more. The hairline cracks in plaster and other finishes affected the appearance of the structure but fortunately did not pose any safety concern Sui Pheng, and Wee, (2001). There were long and continuous cracks across the walls, beams, columns, ceilings and floors. Moreover, a diagonal crack was found at the corner of door where the crack tip was very thin with increased thickness at the initial point.

\subsection{Gap and Detachment}

There were some visible gaps found between the elements, such as walls, columns, beams, ceilings, door frames etc. In fact, there was a new building which had been connected to the original building. However, this new addition was detached from the old building, resulting in a large and visible gap OthumanMydin, and Wang, (2011). A gap was also found between the wall and door frames. Shrinkage and expansion of the door frames (timber materials) due to the atmospheric conditions may result in gap. Besides door frames, other timber materials such as ceiling battens were also found to have gap from the wall. In such circumstances, dampness may penetrate into the building and resulted in water stain. Moreover, column detached from the wall is basically caused by poor construction and workmanship OthumanMydin, (2013).

\subsection{Roof Defects}

Most of the roof systems constructed in each school buildings were pitched roof system. However, there were still flat roof systems in some school buildings. Roof is an important element in a building as it protects the interior from the external weather, such as rain, sunlight and wind Sui Pheng, and Wee, (2001). Different types of roof covering materials were used in each school, such as asbestos, zinc sheets and roof tiles. From the inspections, the roof defects found were the blocked gutters, leaking downpipes, leaking roofs, missing roof tiles, slipping roof tiles and also defective soffit and fascia board. The causes of blocked gutters were the growth of plants and accumulation of leaves and debris. The roof tiles had been put downward towards the gutters and the growth of plants consequently blocked the runway of rainwater. As the result, the rainwater 
will overflow when there was a heavy rain. However, it was also discovered that gutters were not constructed along during the construction stage at some of the school buildings.

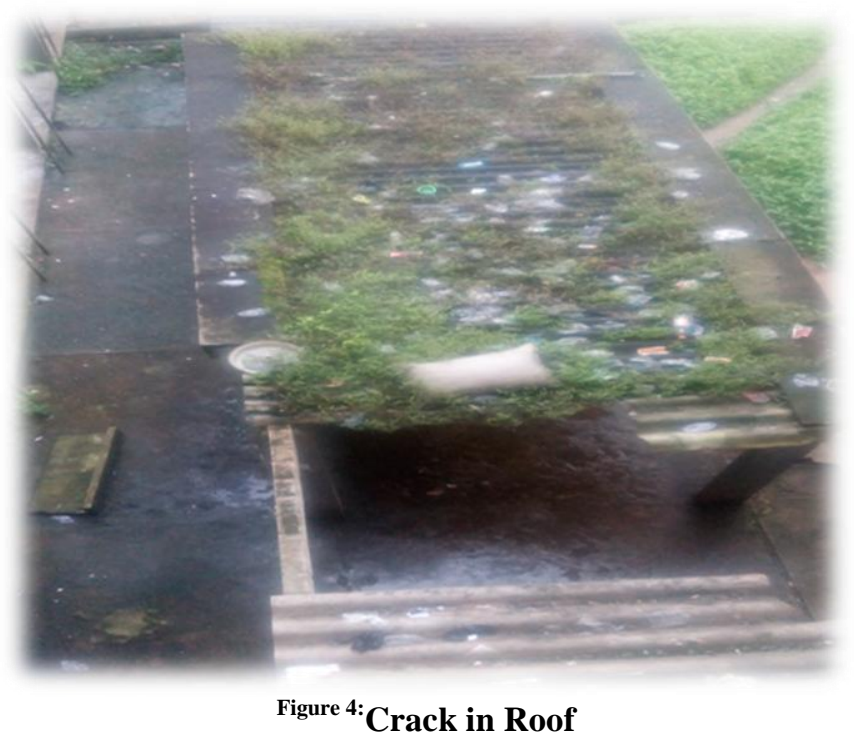

\subsection{Termite Attack}

Timber deteriorated when it exposed to water penetration and excess moisture. Termite attack happened in a damp and digestible timber. Large amount of timber materials had been attacked by termites, causing the timber structures became soft. These materials included timber doors, door frames, roof struts and window frames. Some of the furnitures suffered from this defect as well.

\subsection{Defective Tiles}

Tiles were used as finishes to walls and floors. The types of tiles used in the inspected schools were ceramic tiles and homogenous tiles. There were only certain areas utilized the tiles as finishes because most areas were finished by plaster renderings which were cheaper. Those areas were the offices, cafeteria, computer labs, staff's toilets and multimedia hall. The major problems found in the inspected schools were lip page, unaligned, cracked, broken and loose tiles. Heavy objects dropped on the tiles would crack and break the tiles. Defective tiles can further affect the visual appearance of floors and walls. In brief, this defect was caused by vandalism, impact damage, improper maintenance and poor materials.
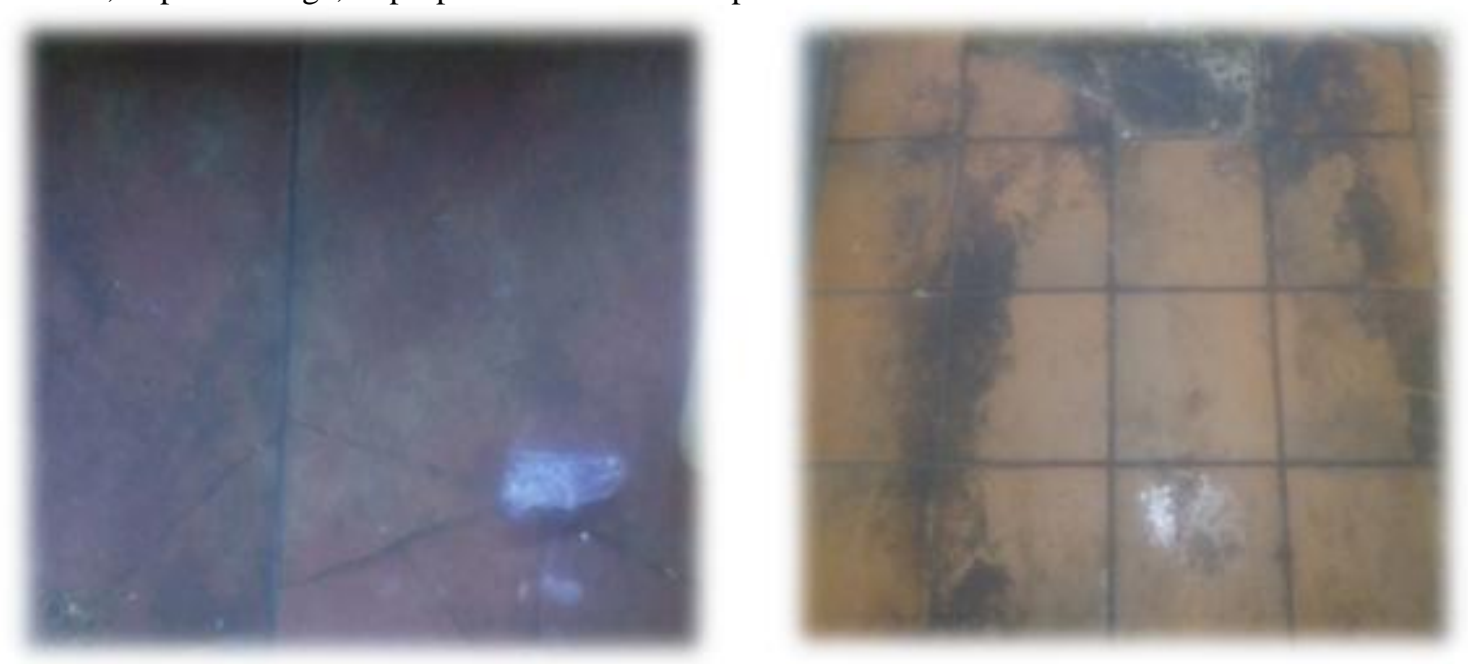

\section{Figure 5; 6: Crack In Floor and Tile}

\subsection{Settlement}

Cracks on the lower parts of the structure indicated the crisis of settlement. The gap of the cracks was large, about $10 \mathrm{~mm}$ and the cracks appeared along the wall of the building. This may be associated with the movement of the ground beneath the foundations due to self-weight of the building. Settlement occurred where

\begin{tabular}{lll}
\hline DOI: $10.9790 / 0837-2108085864$ & www.iosrjournals.org & $62 \mid$ Page
\end{tabular}


a structure found in various ground conditions or foundation failures. Other possible causes of this problem were soil erosion by flowing water, changes in ground water level, uneven bearing capacities of soils and poor soil condition.

\section{Contribution Factors to Building Defects 3.1 Climatic Conditions}

Nigeria is a hot and humid country where heavy rainfall and warm sunshine are all year round(Ikpo Johnson, 2006). This in turn causes the school buildings tend to weather promptly, especially the building materials which are exposed to external elements such as sunlight, rain, wind and atmospheric pollution. In such circumferences, problems such as dampness, mould growth, peeling paint, discoloration and corrosion can easily happen. Defects happened not solely caused by one factors; in fact, they are interlinked.

\subsection{Building Age}

Most of school buildings are more than 30years old. Some of them are even more than 50 years old. The longer a building is exposed to the atmosphere, the higher tendency for it to deteriorate. In point of fact, all elements of school buildings have a tendency to decay at a lesser or greater rate due to aging. For example, timber is basically an aging building material. It will decay after a period of time if no proper inspection and maintenance are conducted.

\subsection{Maintenance of School Buildings}

Most of the schools do not practice scheduled maintenance, but carry out emergency maintenance when necessary, except for the private schools. Formally, public schools have to apply and wait for the allocation from Ministry of Education for the repair and maintenance purposes when problems have occurred. However, private schools perform their maintenance programmes which are more systematic. They conducted scheduled maintenance to every component in schools in order to keep those components in good condition.

\subsection{Poor Workmanship}

Poor workmanship can worsen the building quality and performance, such as poor installation methods, poor mixing of materials, poor handling of materials and poor planning. It is found that the tiles are not installed adequately during the construction stage. In other words, they are not well aligned and untidy. Tiles are used as finishes, therefore, must be able to withstand the heavy impact acting on it as well as enhance its aesthetic value.

\subsection{Insufficient Awareness}

Vandalism is one of the irresponsible actions that can damage the school facilities and infrastructures Ikpo Johnson, (2006). Insufficient awareness and knowledge among the students are the root causes of vandalism. Besides, softer building materials often invite the cases of vandalism. The examples of vandalism are doodle on the walls and bash the doors. Apart from that, the consciousness of school authorities and students in the maintenance aspect is still low. They do not really alert and practice maintenance to look after the schools' facilities and infrastructures. This results in more damages and problems in the building structures.

\section{CONCLUSIONS}

School buildings vastly exposed to all sort of problems due to numerous main factors. Building defects are critical as they can physically affect the building appearance as well as damage the building structure. This can subsequently affect the safety of the building users. Therefore, appropriate solutions to mitigate building defects in schools should be carried out in order to ensure the school buildings do not easily fall into defects. If the defects were not taken seriously, it may consequently lead to structural failure. In brief, all parties such as local government authorities, school authorities, consultants, contractors and public, should be involved in the remedial works and work together in order to diminish the occurrences of defects and failures in school buildings. They should have a close partnership to work mutually in order to form a strong and sustainable built environment in school.

\section{REFERENCES}

[1] Ahmad, A. (2004). Understanding Common Building Defects. Penang, Malaysia,: Dilapidation Survey Report.

[2] Ahzahar, N., Karim, S., \& Hassan, J. E. (2011). A study of Contribution Factors to Building Failures and Defects in Construction Industry. Procedia Engineering, 20, 249-255.

[3] Chong, W., \& Low, S. (2006). Latent Building Defects: Causes and Design Strategies to Prevent Them,. Journal of Performance of Constructed Facilities, 20(3), 213-221.

[4] Ikpo Johnson, I. (2006). Building Maintenance Management. Calabar: Manson Publishing Company.

DOI: 10.9790/0837-2108085864 $\quad$ www.iosrjournals.org $63 \mid$ Page


[5] Mohd Isa, H. P., Hassan, M. C., \& Z, I. Z. (2011). Learning from Defects in Design and Build Hospital Projects in Malaysia,. International Conference on Social Science and Humanity, 5, 238-242.

[6] Othuman Mydin, M. (2013). An Experimental Investigation on Thermal Conductivity of Lightweight Foamed concrete for Thermal Insulation. Jurnal Teknologi, 63(1), 43-49.

[7] Othuman Mydin, M. (2013). Modeling of Transient Heat Transfer in Foamed Concrete Slab. Journal of Engineering Science and Technology, 8(3), 331-349.

[8] Othuman Mydin, M., \& Wang, Y. (2011). Structural Performance of Lightweight Steel-Foamed Concrete-Steel Composite Walling System under Compression. Journal of Thin-walled Structures, 49(1), 66-76.

[9] Soleimanzadeh, S., \& Othuman Mydin, M. (2013). Influence of High Temperatures on Flexural Strength of Foamed Concrete Containing Fly Ash and Polypropylene Fiber,. International Journal of Engineering,,

[10] Sui Pheng, L. D. (2001). Improving maintenance and reducing building defects through ISO 9000 Journal of Quality in Maintenance Engineering, 7(1), 6-24.

[11] Yuseni, A., \& Abd Samad, H. (2013). Building Maintenance Management Preliminary Finding of a Case Study in Icym,. Middle-East Journal of Scientific Research, 17(9), 1260-1268. 